\title{
Parapneumonic pleural effusion: reality and strategies in an Amazon university hospital
}

\section{Derrame pleural parapneumônico: realidade e estratégias em um hospital universitário na Amazônia}

Claudia Giselle Santos Aréaš2; Geraldo Roger Normando Júnior, TCBC-PA; Orlando Sandoval Farias Júnior; irna Carla Do Rosário Souza CARNEIRO ${ }^{2}$

\begin{abstract}
A B S T R A C T
Objective: to define the profile and analyze the postoperative evolution of children with parapneumonic pleural effusion (PPE), and to evaluate strategies used in the presence of diagnostic and therapeutic limitations, emphasizing the open thoracic drainage (OTD). Methods: we conducted a cross-sectional, prospective, analytical study in which we followed children admitted in an Amazon university hospital with surgically addressed PPE, from October 2010 to October 2011. Results: we studied 46 patients, most children under three years of age $(74 \%)$, with no gender predominance. A significant portion of the sample (28\%) had inappropriate body mass index. We found short stature in five patients (11\%), which tended, in general, to a worst postoperative outcome when compared with children of normal height $(p=0.039)$. The average duration of symptoms till admission was 16.9 days. Empyema was a common diagnosis in the first surgery (47.8\%), and its bearers had longer duration of chest tube drainage $(p=0.015)$. Most children (80.4\%) were operated only once. The mean length of hospital stay was 25.9 days. Thoracic drainage (water-sealed) was the most common procedure (85\%), with conversion to OTD in $24 \%$ of the sample, thoracotomy being rare (4\%). There were no deaths. Conclusion: the studied individuals often had advanced disease and nutritional disorders, affecting outcome. OTD remains a valid option for specific situations, and further studies are needed for confirmation.
\end{abstract}

Keywords: Pneumonia. Pleural Effusion. Empyema, Pleural. Child. Thoracic Surgery.

\section{INTRODUCTION}

Preur neumonia, a common and potentially severe disease in children, accounts for about 1.9 million deaths a year worldwide. Most fatal cases occur in poor countries, where underreporting is an additional negative factor ${ }^{1}$. In Brazil, despite the overall reduction in pneumonia deaths in young children, a high mortality rate persists, with discrepancies between different regions. The rate found in the North corresponds to that found in the South eight years ago 2,3 . There has been an overall increase in the incidence of pneumonic complications, particularly the parapneumonic pleural effusion (PPE) ${ }^{4}$.

PPE is classified as complicated and non-complicated. The non-complicated is an exudative reaction to the adjacent pulmonary infection and, in general, is reabsorbed with antibiotic treatment and cure of pulmonary infection. It is a non-purulent effusion, with no germs on direct examination (Gram) or culture.
The complicated PPE is purulent, somewhat opaque, or presents germs on culture or Gram. The empyema, defined as the accumulation of intrapleural pus, is the typical complicated PPE 5 .

PPE has been the source of several studies in recent decades. Not without much discussion, the evidence established a relative standardization for its diagnosis and treatment. In this context, useful are the ultrasound, the use of fibrinolytic agents and early debridement of the pleural cavity by Video-Assisted Thoracoscopic Surgery (VATS) 5 .

The João de Barros Barreto University Hospital (HUJBB/UFPA), an Amazon reference in infectious diseases, has a large number of pediatric admissions due to pneumonia complications. A local preliminary study in 2010 revealed, in addition to a high children prevalence of PPE, the lack of permanent availability of ultrasound, of fibrinolytic agents or VATS for the population. It also observed the use of water-sealed Closed Thoracic Drainage (CTD) in most cases, and the

1 - Federal University of Pará, João de Barros Barreto University Hospital, Belém, Pará State, Brazil. 2 - Federal University of Pará, Health Sciences Institute, Belém, Pará State, Brazil. 3 - Para State University, Faculty of Medicine, Belém, Pará State, Brazil. 
conversion into open thoracic drainage (OTD) for the refractories. It also found that classic thoracotomy was hardly performed, and yet the discharge of patients in good general condition was the rule.

Thus, it has become imperative to study this pediatric population treated in lack of what is ideally established by the recent literature. It is necessary to define the role of OTD in the discharge of these children and their subsequent return to school and family life, concomitantly with their characterization, whose regional peculiarities are little known by the small number of related publications.

\section{METHODS}

We prospectively followed all pediatric patients admitted to HUJBB/UFPA diagnosed with PPE, who suffered any surgical intervention, in the period between October 2010 and October 2011. The sample was of children coming from other smaller hospitals of the Unified Health System (SUS, where they await availability of bed in the institution where the research took place. We continued follow-up until April 2012, through periodic access to outpatient medical records after discharge. The minimum admission followup until outpatient discharge was 1.6 months, and maximum, 6.2 months, with an average of 3.3. We excluded children whose effusion had non-pneumonic causes and cases with conservatively treated PPE.

\section{Local Protocol}

After the PPE diagnosis, when in moderate size according to the judgment of the thoracic surgery team, puncture is immediately indicated under local anesthesia and sedation. At that time, purulent liquid or any turbidity indicates immediate CTD, which is also held in relapses of previously evacuated effusions. The drain is maintained while the output remains liquid or air, and is removed when the flow ceases, with underlying pulmonary expansion.

In refractory cases, when there is no postoperative lung expansion after fifteen days due to the organization of empyema and pleural thickening, CTD is converted to OTD. We use the OTD term instead of the classic term "pleurostomy" or "open thoracostomy" because, unlike the latter, there is no rib resection, or even a muscular approach. Simply, the drain is cut about three centimeters above the skin, at the bedside. This drain segment is usually removed after hospital discharge, during the consultation at the clinic, when there is confirmation of adequate pulmonary re-expansion.

Because there is no availability of VATS for pediatric patients, pulmonary decortication is performed by classical thoracotomy, and therefore is reserved for use only in extreme cases that do not respond to the described protocol, or have dramatically unfavorable evolution. The patients admitted already with CTD, held in the source hospitals, are conducted similarly.

\section{Variables studied}

We studied age, gender, origin, nutritional status, previous surgery, duration of symptoms until admission, fever, hospital stay, time of thoracic drainage, macroscopic appearance of effusion, performed surgeries and postoperative outcome.

\section{Data analysis}

We organized a database using Epi Info version 3.5.1. All analyzes were conducted in $R(R$ Core Team, Vienna, Austria). We performed statistical analyzes using Student's t test for quantitative variables and $\mathrm{G}$ test, and the $X^{2}$, to compare categorical variables. We defined statistical significance as $\mathrm{p} \leq 0.05$.

\section{Ethical aspects}

All stages of the study were assessed and approved by the Ethics in Research Committee of the João de Barros Barreto University Hospital, Federal University of Pará, Brazil (Protocol no 2161/2010-CEP/HUJBB).

\section{RESULTS}

We followed 46 patients. There was no gender predominance, and more than half, 25 (54.3\%) was from the interior of the state.

The mean age was 2.7 years $( \pm 2.4)$, the youngest child was two months-old and the oldest, 12.4 years-old. The majority had less than five years 
of age (87\%) and $74 \%$, less than three. Infants (up to two years) composed $46 \%$ of the sample (Figure 1).

Regarding nutritional status, five patients (11\%) had low stature, and was found inadequacy of body mass index (BMI) in 13 subjects (28\%), thinness being slightly more present than overweight (7 vs. 5 patients).

The average duration of symptoms until admission was 16.9 days (5-45 days range). Eleven (24\%) children had already been operated (CTD) in the local hospital. In 22 individuals pleural effusion was grossly purulent at the first procedure in HUJJ/UFPA, having been characterized as "empyema".

The study group had 56 surgical performed procedures, which corresponds to 1.2 surgeries per child in the sample. Only nine of the 46 children were subjected to more than one operation, which means that $80 \%$ of the sample had only one operation, showing success of the initial procedure in these patients (Figure 2).

The first surgery was CTD in 39 patients, alone or preceded by chest puncture on the same occasion. Isolated puncture or thoracentesis occurred as the initial procedure in five $(11 \%)$ patients, and classical thoracotomy with decortication in two (4\%). These two serious patients had been admitted already with CTD (Figure 3). In the nine cases in which a single surgery was not enough, CTD was also the most common surgical procedure, being performed on five of these children.

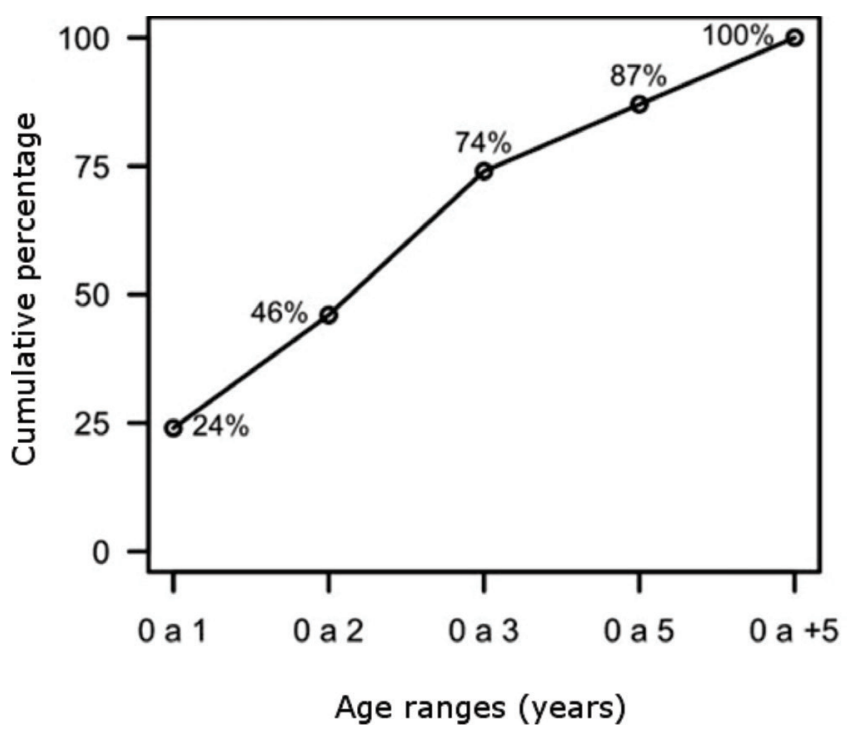

Figure 1. Cumulative percentage of patients' ages (years).
Considering the whole sample, 11 patients required OTD at some time during hospital stay. Only one had the drain removed during hospitalization and the remaining ten were discharged bearing the device segment, subsequently withdrawn in the clinic.

The postoperative course was classified into four levels: (i) discharge without OTD, (ii) OTD / discharge without drain, (iii) OTD / discharge with drain; and (iv) multiple surgeries. The first three groups were subjected to only one surgical-anesthetic procedure, progressing in descending order of therapeutic success, all being better, however, than the latter group, in which individuals were operated more than once. We observed that, in general, children with normal height for the age progressed more satisfactorily (Test $G=8.36 ; p=0.039$ ) (Figure 2).

The average number of days that patients were in CTD was 12 (2-38). The average time with draining devices (CTD or OTD) in the pleural space was 14 days. After conversion from CTD to OTD, patients stayed in hospital for more 4.8 days on average.

There was a significant difference regarding thoracic drainage time and purulent effusion (t test $=2.54$, $p=0.015)$, showing that patients with empyema at the first procedure had longer drainage time (Figure 3).

The average hospitalization time was 25.9 days (7-86). We found no correlation between the length of stay and the other variables.

\section{DISCUSSION}

As opposed to the male predominance among children with PPE demonstrated in most populations studied, in this study there was no gender

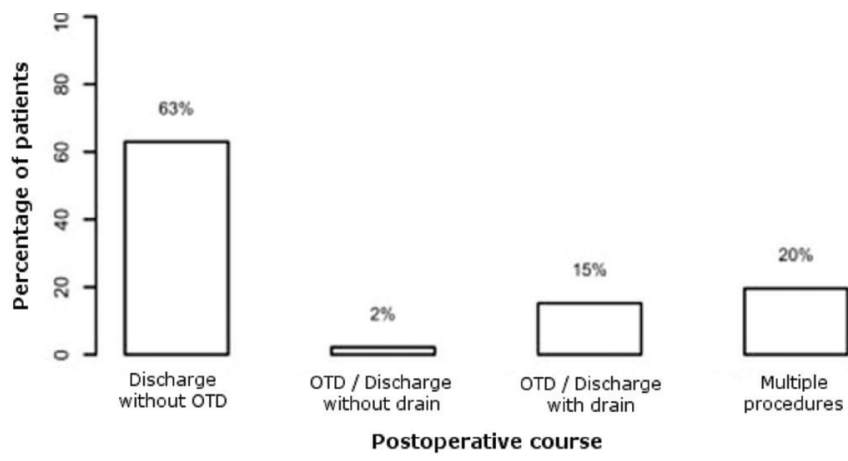

Figure 2. Percentage of patients according to postoperative evolution. 


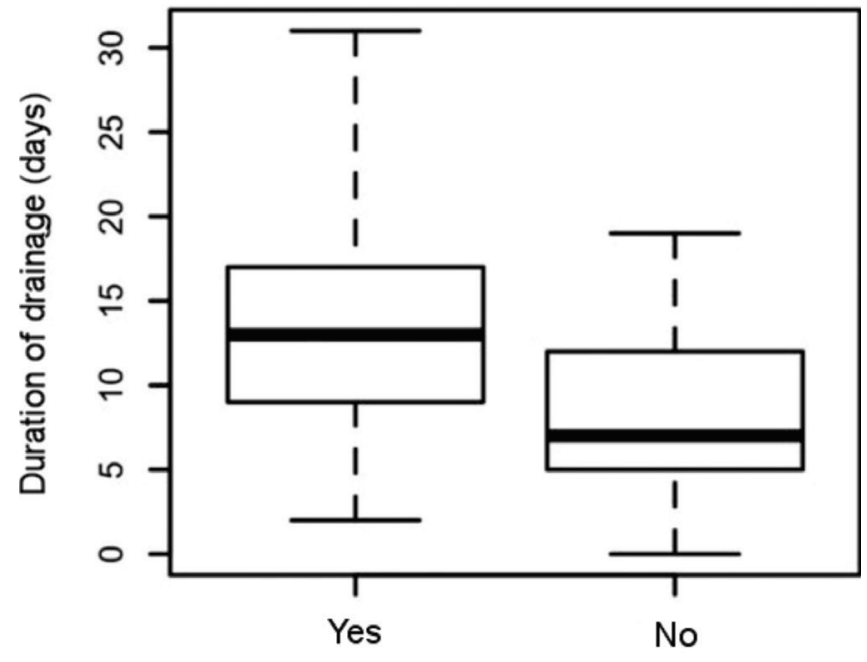

Purulent fluid

Figure 3. Characterization of drainage duration (days) in relation to the occurrence of purulent effusion, in which a difference was found between the groups (Student's t test $=2.54, p=0.015$ ).

predominance $^{6-8}$. Most international studies, although stating that pneumonic complications significantly affect young children, found higher mean age (4-7.6 years), and lower proportion of infants and preschool children than in our study, in which $87 \%$ had less than five years. This trend, however, is in agreement with that reported by Brazilian literature, with an average age between two and 2.9 years ${ }^{4-11}$.

The prevalence of short stature is higher than the national average (11\% vs. $7.2 \%$ ). Considering the strong tendency of reduction of the the prevalence of height deficit with increasing income, we can conclude that, at least in part, socioeconomic factors are major determinants of high malnutrition rate in the initial physical examination of children admitted to HUJBB, a known reference hospital of the Unified Health System (SUS), where the disadvantaged population economically is the rule ${ }^{12}$. Children of normal height showed better postoperative outcome. One could also expected them to present a shorter hospital stay and fever time, though this did not happen. One would probably observe this with a longer study period and therefore with a larger sample ${ }^{13}$.

The disease duration until hospital admission was 16.9 days, this delay being greater than the one reported in the literature (6.4 to 15 days). Unfortunately, the evolution of PPE bearers is worse when this time is greater than four days, which may explain the high prevalence of complicated PPE and empyema ${ }^{13}$.

The delay in the transfer of patients to the tertiary hospital is remarkable. In Pará, the difficulties begin well before admission. The State is more than twice the size of France, with extreme difficulty of transportation in the region dominated by the Amazon forest and its rivers, where more than half the population (52.4\%) live below the poverty line, and has just over two hospital beds per thousand inhabitants and ${ }^{13-15}$.

The duration of fever after hospital admission was 9.8 days on average, agreeing with the reported in the literature (4.2 to 12.8 days $)^{7,9,16}$.

A considerable amount of children gets to HUJBB after going through some kind of operation to approach the pleural effusion. Thus, $24 \%$ of patients had undergone a surgical procedure in origin hospital. In fact, the children take so long awaiting transfer to the reference hospital that it is no longer rare that they have been operated in those institutions. Although after hospitalization they are all conducted in a similar manner, this is an important limitation of this study.

In almost half of the children, we observed grossly purulent pleural fluid in the initial procedure, a proportion higher than the one found in the literature (15.5 to $33 \%)$. The considerable waiting for definitive treatment justifies this finding so unfavorable to early cure?

Ultrasonography has high sensitivity in the staging of effusion. One study demonstrated that although only $12 \%$ of children with PPE had empyema, $65.6 \%$ already had septa in the thoracic sonography before the procedure. Unfortunately, this diagnostic feature is not part of the routine in HUJBB due to its limited availability. It is worrisome to think that the proportion of patients admitted with effusion in organizational stage is unknown, though probably enormous, as evidenced by the high frequency of frankly purulent liquid in the first procedure ${ }^{14}$.

A large portion of the sample (80.4\%) undergone only one operation, featuring success of the initial procedure. Today, there are few studies using only CTD, without VATS, fibrinolytic agents or topical saline, at least. A study published by Soares et 
al. ${ }^{7}$ is one of them, and therefore allows comparisons as for the success of the first operation. In it, $52 \%$ of children with PPE were subjected to CTD, and $18 \%$ of the sample went through another procedure, mostly classical thoracotomy. In our study, however, this most dramatic feature was used only twice $(4.3 \%)$ and also in two cases operated the first time at other institutions.

The striking prevalence of empyema, just to mention one of the evidence of disease severity, denies any assumption that the followed cases were in the early stage of complication, which would justify the low indication of thoracotomy. We assume that this can be attributed to the appropriate conversion of CTD to OTD described in patients the prolonged evolution, which prevents patients from undergoing more aggressive interventions and their possible consequences (postoperative in Intensive Care Units, transfusions of blood products, vigorous analgesia, insertion of deep venous catheters, etc. $)^{7,17}$.

In another national study, Freitas et al. ${ }^{8}$ achieved an even higher rate of cure with only one procedure (88\%). In this multi-institutional study, they analyzed cases of PPE in the fibrinopurulent stage, using VATS as the initial approach. It is one of the few investigations that uses pleurostomy, although limited to cases refractory to VATS, with good results.

We did not use pleurostomy in this study, as it is not part of HUJBB protocol for pediatric PPE. The transformation of CTD in OTD, described above, does not involve going to the operating room or anesthesia, since it comprises the simple section of the device next to the chest wall. Moreover, we did not use any kind of open thoracic window prosthesis, although there have been good results with this feature in adults, and the reasonably wide drain seems to guarantee the viability and persistence of the stoma ${ }^{17,18}$.

Certainly, the OTD described may not contribute as much as early VATS would to the reduction of hospital stay and costs. However, it allowed several children to return to their homes, as all had clinical and radiological recovery within four months after discharge, with no deaths.

In conclusion, the HUJBB faces enormous difficulties in managing the considerable number of pediatric patients with severe pneumonic complications, pleural effusion. This population is mostly of young children, with long time until admission, usually approached with advanced disease, and high prevalence of nutritional disorders, which seems to contribute to prolonged hospital stay and duration of chest drainage. However, they usually undergo only one surgicalanesthetic procedure, and hospital discharge is commonly obtained by converting closed chest drainage to an open one. This strategy seems to be valid for these patients in the absence of the most modern and resources that the evidence recommends. They rehabilitate and return to their usual activities, though further studies are needed to confirm this assumption. Thus, this study may be useful in guiding alternative conducts to the equally disadvantaged hospitals in the North, or even in other regions of the country, while there is no availability of instruments that allow the application of the guidelines proposed by the current literature, with real benefit to the pediatric population.

\title{
R E S U M O
}

\begin{abstract}
Objetivo: definir o perfil e analisar a evolução pós-operatória de crianças com derrame pleural parapneumônico (DPP), bem como, avaliar estratégias utilizadas na vigência de limitações diagnóstico-terapêuticas, enfatizando a drenagem torácica aberta (DTA). Métodos: estudo transversal, prospectivo, analítico, no qual foram acompanhadas as crianças admitidas em um hospital universitário da Amazônia com o diagnóstico de DPP abordado cirurgicamente, no período entre outubro de 2010 a outubro de 2011. Resultados: foram estudados 46 pacientes, a maioria menor de três anos de idade (74\%), sem predominância de sexo. Significativa parcela da amostra (28\%) possuía índice de massa corpórea inadequado. Baixa estatura foi encontrada em cinco pacientes (11\%), que tenderam, em geral, à pior evolução pós-operatória, quando comparados com as crianças de estatura normal $(p=0,039)$. A duração média dos sintomas à admissão foi 16,9 dias. O empiema foi diagnóstico comum na primeira intervenção cirúrgica (47,8\%), e seus portadores apresentaram maior duração da drenagem torácica $(p=0,015)$. A maioria das crianças $(80,4 \%)$ foi operada apenas uma vez. A média de dias de internação hospitalar foi 25,9 dias. A drenagem torácica fechada em selo d'água foi a cirurgia mais realizada (85\%), precisando ser convertida em DTA em $24 \%$ da amostra e toracotomias foram raras (4\%). Não houve óbitos. Conclusão: os indivíduos estudados possuíam frequentemente doença avançada e distúrbios nutricionais, repercutindo na evolução clínica. A DTA permanece como uma opção válida para situações específicas, e novos estudos ainda são necessários para confirmação.
\end{abstract}

Descritores: Pneumonia. Derrame Pleural. Empiema Pleural. Criança. Cirurgia Torácica. 


\section{REFERENCES}

1. Leung DT, Chisti MJ, Pavia AT. Prevention and control of childhood pneumonia and diarrhea. Pediatr Clin North Am. 2016;63(1):67-79.

2. Axelsson I, Silfverdal SA. Pneumonia mortality among children in Brazil: a success story. J Pediatr (Rio J). 2011;87(2):85-7.

3. Rodrigues FE, Tatto RB, Vauchinski L, Leães LM, Rodrigues MM, Rodrigues VB, et al. Pneumonia mortality in Brazilian children aged 4 years and younger. J Pediatr (Rio J). 2011;87(2):111-4.

4. Yu D, Buchvald F, Brandt B, Nielsen KG. Seventeen-year study shows rise in parapneumonic effusion and empyema with higher treatment failure after chest tube drainage. Acta Paediatr. 2014;103(1):93-9.

5. Islam S, Calkins CM, Goldin AB, Chen C, Downard $C D$, Huang $E Y$, et al. The diagnosis and management of empyema in children: a comprehensive review from the APSA Outcomes and Clinical Trials Committee. J Pediatr Surg. 2012;47(11):2101-10.

6. Langley JM, Kellner JD, Solomon N, Robinson JL, Le Saux N, McDonald J, et al. Empyema associated with community-acquired pneumonia: a Pediatric Investigator's Collaborative Network on Infections in Canada (PICNIC) study. BMC Infect Dis. 2008;8:129.

7. Soares P, Barreira J, Pissarra S, Nunes T, Azevedo I, Vaz L. Derrames pleurais parapneumónicos em pediatria: experiência num hospital central universitário. Rev Port Pneumol. 2009;15(2):241-59.

8. Freitas S, Fraga JC, Canani F. Toracoscopia em crianças com derrame pleural parapneumônico complicado na fase fibrinopurulenta: estudo multi-institucional. J Bras Pneumol. 2009;35(7):660-8.

9. Westphal FL, Lima LC, Netto JCL, Tavares E, Andrade EO, Silva Mdos S. Surgical treatment of children with necrotizing pneumonia. J Bras Pneumol. 2010;36(6):716-23.

10. Amorim PG, Morcillo AM, Tresoldi AT, Fraga Ade M, Pereira RM, Baracat EC. Factors associated with complications of community-acquired pneumonia in preschool children. J Bras Pneumol. 2012;38(5):614-21.
11. Moreira GO, Ribeiro JD, Tresoldi AT. Utility of a scoring system and indicative variables for assessing the need for pleural drainage in pediatric patients with parapenumonic pleural effusion. J Bras Pneumol. 2005;31(3):205-11.

12. IBGE. Instituto Brasileiro de Geografia e Estatística. Consumer Expenditure Survey 2008-2009 Anthropometry and nutritional status of children, teenagers and adult in Brazil, 2010.

13. Chisti MJ, Tebruegge M, La Vincente S, Graham SM, Duke T. Pneumonia in severely malnourished children in developing countries - mortality risk, aetiology and validity of WHO clinical signs: a systematic review. Trop Med Int Health. 2009;14(10):173-89.

14. Becker A, Amantéa SL, Fraga JC, Zanella MI. Impact of antibiotic therapy on laboratory analysis of parapneumonic pleural fluid in children. J Pediatr Surg. 2011;46(3):452-7.

15. IBGE. Instituto Brasileiro de Geografia e Estatística. Summary of Social Indicators: An analysis of the Brazilian population life conditions 2010.

16. Picard E, Joseph L, Goldberg S, Mimouni FB, Deeb $M$, Kleid $D$, et al. Predictive factors of morbidity in childhood parapneumonic effusion-associated pneumonia: a retrospective study. Pediatr Infect Dis J. 2010; 29(9):840-3.

17. Fraga JC, Kim P. Abordagem cirúrgica da efusão pleural parapneumônica e suas complicações. J Pediatr (Rio J). 2002;78 Suppl 2:161-70.

18. Filomeno LTB, Campos JRM, Machuca TN, Neves-Pereira JC, Terra RM. Prosthesis for open pleurostomy (POP): management for chronic empyemas. Clinics (São Paulo). 2009;64(3):203-8.

Received in: 11/08/2016

Accepted for publication: 01/10/2016

Conflict of interest: none.

Source of funding: none.

\section{Mailing address:}

Claudia Giselle Santos Arêas

E-mail: claudiaareas@gmail.com claudiaareas@ufpa.br 